Table 1. Demographic data

\begin{tabular}{ccc}
\hline Variable & Low disease activity & High disease activity \\
\hline Mean age (years) & 38.1 & 40.0 \\
\% Female & 90.7 & 88.2 \\
\% White/Caucasian & 76.7 & 67.7 \\
Mean years diagnosed & 5.5 & 5.0 \\
\hline
\end{tabular}

Table 2. Propensity score matching results

\begin{tabular}{|c|c|c|c|c|c|}
\hline Outcome variable & $\begin{array}{l}\text { Low activ- } \\
\text { ity mean }\end{array}$ & $\begin{array}{l}\text { High activ- } \\
\text { ity mean }\end{array}$ & Coefficient & $95 \% \mathrm{Cl}$ & p-value \\
\hline Flared in the last 12 months & 11.63 & 37.97 & -0.26 & {$[-0.38--0.14]$} & ] $<0.001$ \\
\hline Number of flares in last 12 months & 0.21 & 0.70 & -0.49 & {$[-0.72--0.26]$} & ] $<0.001$ \\
\hline Hospitalised in last 12 months & 4.65 & 14.98 & -0.10 & {$[-0.17--0.04]$} & 0.001 \\
\hline $\begin{array}{c}\text { Number of consults in last } 12 \\
\text { months }\end{array}$ & 2.84 & 3.52 & -0.68 & {$[-1.19--0.17]$} & 0.009 \\
\hline EQ-5D-3L & 0.78 & 0.88 & 0.10 & {$[0.03-0.17]$} & 0.004 \\
\hline FACIT Fatigue & 34.68 & 39.86 & 5.19 & {$[0.80-9.57]$} & 0.02 \\
\hline $\begin{array}{l}\text { WPAI overall percentage work } \\
\text { impairment }\end{array}$ & 14.42 & 45.35 & -30.93 & $\begin{array}{c}{[-45.32} \\
--16.54]\end{array}$ & $<0.001$ \\
\hline
\end{tabular}

Conclusion: Systemic lupus erythematosus patients with lower levels of disease activity are less burdensome to the healthcare system and experience a significantly better HRQoL and lower levels of productivity impairment. There is a need to establish a universal definition of low disease activity as a treatment goal to benefit patient quality of life and reduce HCRU.

Study funded by Johnson and Johnson.

Disclosure of Interests: Zahi Touma Consultant of: Consultant for Janssen, Ben Hoskin Consultant of: Consultant for Janssen, Christian Atkinson Consultant of: Consultant for Janssen, David Bell Consultant of: Janssen, James Pike Consultant of: Janssen, Jennifer H. Lofland Employee of: Janssen, Pamela Berry Employee of: Janssen, Chetan Karyekar Shareholder of: Johnson \& Johnson, Consultant of: Janssen, Employee of: Janssen Global Services, LLC. Previously, Novartis, Bristol-Myers Squibb, and Abbott Labs., Karen Costenbader Grant/ research support from: Merck, Consultant of: Astra-Zeneca

DOI: 10.1136/annrheumdis-2020-eular.5872

\section{AB1171 EFFECTS OF SUCCESSIVE SWITCHES OF TWO DIFFERENT BIOSIMILARS OF ETANERCEPT ON OUTCOMES IN INFLAMMATORY RHEUMATIC DISEASES IN DAILY PRACTICE}

U. Kiltz, S. Tsiami, X. Baraliakos, J. Braun. Rheumazentrum Ruhrgebiet, Herne, and Ruhr-University Bochum, Germany

Background: A single switch from an originator to a biosimilar product has been shown to be safe and effective in the treatment of rheumatic musculoskeletal diseases (RMDs). The availability of biosimilars has created a financial incentive to encourage switching to cheaper products ("non-medical switch"). This is naturally associated with multiple switches. However, the effect of multiple switching between biosimilars of the same reference product has not been thoroughly investigated to date.

Objectives: To assess the effectiveness and safety of systematic non-medical switching from innovator etanercept (ETN) to biosimilar ETN (SB4) and successive to another biosimilar ETN (GP2015) in adult patients with rheumatoid arthritis (RA), psoriatic arthritis (PsA) or axial spondyloarthritis (axSpA) in a real-life setting.

Methods: This retrospective study was performed in a tertiary center in adult patients with RA, PsA or axSpA who had been treated with the innovator ETN and who had been switched to two ETN biosimilars for economic reasons thereafter. The first switch from innovator ETN to the first biosimilar ETN occurred between February-May 2017 and the second switch from the first to the second biosimilar ETN occurred between September-December 2017. The end of the observation period was October 2019. Disease activity, function and adverse events (AE) were regularly assessed, and any changes in outcome were recorded during the follow-up period. The scores documented at week 12 week after the second switch were taken as primary outcome. A total of 100 patients (54 RA, 27 axSpA, 19 PsA, mean age $54.3 \pm 15.1$, 46\% male) who switched twice to those ETN biosimilars over a follow-up period of $21.1 \pm 7.4$ months were included. The retention rate after the second ETN biosimilar switch was $89 \%$ about 6 months after the second switch. While 2 patients were lost to follow-up and 1 patient died (cardiac arrest), 7 patients discontinued due to inefficacy or AE, including one pancreatic cancer. One patient was withdrawn due to pregnancy. Overall, 14 AEs were reported in 8 patients. Among them, 4 patients switched back to originator etanercept in month 6, 1 patient re-administered GP2015 successfully in month 3 after suffering from mucosal erosions and in 3 patients another mode of action was prescribed. The scores at week 12 of both, disease activity and function, remained unchanged (Table 1).

Table 1. Patient characteristics

\begin{tabular}{|c|c|c|c|c|c|c|c|}
\hline & Assessment & $\begin{array}{c}\text { Baseline } \\
(n=100)\end{array}$ & $\begin{array}{c}\text { SB4 } \\
\text { Follow-up } \\
12 \text { weeks } \\
(n=100)\end{array}$ & $\begin{array}{c}\text { SB } 4 \\
\text { Follow-up } \\
24 \text { weeks } \\
(n=100)\end{array}$ & $\begin{array}{l}\text { Second } \\
\text { switch to } \\
\text { GP2015 } \\
(n=100)\end{array}$ & $\begin{array}{c}\text { GP2015 } \\
\text { Follow-up } \\
12 \text { weeks } \\
(n=97)\end{array}$ & $\begin{array}{c}\text { GP2015 } \\
\text { Follow-up } \\
24 \text { weeks } \\
(n=89)\end{array}$ \\
\hline \multirow[t]{2}{*}{ RA } & DAS28 & $3,0(1,2)$ & $2,9(1,4)$ & $3,1(1,2)$ & $2,8(1,4)$ & $3,4(2,5)$ & $3,0(1,4)$ \\
\hline & $\mathrm{HAQ}$ & $1,4(0,8)$ & $1,6(0,9)$ & $1,0(0,9)$ & $1,5(0,8)$ & $1,5(0,8)$ & $1,6(0,9)$ \\
\hline \multirow[t]{2}{*}{ PsA } & DAS28 & $3,8(1,4)$ & $1,9(1,4)$ & $2,8(1,5)$ & $3,1(1,1)$ & $4,5(2,6)$ & $3,6(2,6)$ \\
\hline & $\mathrm{HAQ}$ & $1,2(0,9)$ & $1,0(0,9)$ & $0,9(0,9)$ & $1,0(0,8)$ & $1,0(0,9)$ & $1,2(0,8)$ \\
\hline \multirow[t]{3}{*}{ axSpA } & BASDAI & $5,1(2,7)$ & $4,5(2,6)$ & $5,1(3,8)$ & $4,1(2,2)$ & $4,6(2,5)$ & $4,3(2,4)$ \\
\hline & ASDAS & $3,4(0,8)$ & $2,5(0,8)$ & $2,7(0,8)$ & $3,2(1,8)$ & $2,7(1,2)$ & $2,5(0,9)$ \\
\hline & BASFI & $4,4(2,7)$ & $4,3(2,7)$ & 4,3 (3,2) & $4,6(2,6)$ & $4,5(2,7)$ & $4,8(3,0)$ \\
\hline
\end{tabular}

*Values are mean \pm standard deviation

Disclosure: Hexal funded this research

Conclusion: The retention rate after multiple switches from innovator ETN to two ETN biosimilars was close to $90 \%$. No major changes in disease activity and function were observed in all three indications.

\section{AB1172 IMPROVEMENT OF DEPRESSION BY JOINT SURGERY IN ESTABLISHED RHEUMATOID ARTHRITIS; RESULTS FROM MULTICENTER PROSPECTIVE COHORT STUDY FOR EVALUATION OF JOINT SURGERY ON PATIENT'S REPORTED OUTCOME}

T. Kojima ${ }^{1}$, M. Kojima ${ }^{2}$, H. Ishikawa ${ }^{3}$, K. Nishida ${ }^{4}$, S. Asai ${ }^{1}$, N. Ishiguro ${ }^{1}$.

${ }^{1}$ Nagoya University Hospital, Orthopedic Surgery/Rheumatology, Nagoya,

Japan; ${ }^{2}$ Nagoya City University Graduate School of Medical Science, Nagoya,

Japan; ${ }^{3}$ Niigata Rheumatic Center, Shibata, Japan; ${ }^{4}$ Okayama University

Graduate School of Medicine, Dentistry and Pharmaceutical Sciences,

Okayama, Japan

Background: Total management including reconstructive joint surgery and rehabilitation should be needed for further improvements of physical function for long-standing RA patients. In these days, it is very important to evaluate the effectiveness of joint surgery as well as drug therapy based on patient-reported outcome (PRO)

Objectives: The purpose of this study is to explore the relationship among depression, clinical variables and other PROs including physical function and to explore whether joint surgery can improve the depression.

Methods: Multicenter prospective observational cohort study was conducted among patients who underwent elective joint surgery for RA from April 2012 to March 2016 (Study registration: UMIN000012649). In this study, we collected data at baseline and at 6 or 12 months after the surgery. These data were as follow; age, sex, disease duration, drug therapies, and disease activity (DAS), TUG, and patient-reported outcome [HAQ-DI, EQ-5D (QOL), pain and BDI-II (depression)]. Correlation between BDI-II and other variables were determined using multiple liner regression analysis.

Results: Totally, 346 patients before elective joint surgery were analyzed cross-sectionally. Mean age, disease duration, pain VAS, DAS28, HAQ-DI, EQ-5D and BDI-II were 64.2 years, 17.0 years, $36.2 \mathrm{~mm}, 3.02,1.11,0.641$ and 13.0, respectively. $52.6 \%$ of elective joint surgeries were in upper limbs and $47.4 \%$ were in lower limbs. Multiple liner regression analysis showed that HAQ-DI [B:0.099 (95\%Cl:-0.117- -0.08) B:-0.48] pain VAS [B:-0.002 (95\%Cl:-0.002- -0.001) $\beta:-0.26]$ and BDI-II [B:-0.003 (95\%Cl:-0.005- -0.002) $\beta:-0.19]$ had significant impact on EQ-5D. Furthermore, HAQ-DI [B:3.78 (95\%Cl:2.54- 5.06) $\beta: 0.33]$ and pain VAS [B: 0.062 (95\% Cl: 0.023- 0.101) $\beta$ 0.17] had significant impact on BDI-II. Especially, walking and eating were independent factors for BDI-II in HAQ-DI categories. These results were confirmed in longitudinal analyses using results from joint surgery in lower limbs (LL; $n=138$ ) and upper limbs (UL; $n=165)$, respectively. BDI-II was remarkably improved from 12.1 (mean) to 10.5 in LL and from 14.2 (mean) to 11.9 in UL. Change in HAQ-DI had significant impact on that in BDI-II [LL; B:3.183 (95\%Cl:0.301- 6.065) ß:0.229, and UL; B:2.55 (95\%Cl:0.194.92) $\beta: 0.19]$ while that in painVAS did not. Especially, the improving in walking category by LL [B:1.38 $(95 \% \mathrm{Cl}: 0.06-2.70) \beta: 0.18]$ and in hygiene category by UL [B:2.11 (95\%Cl:0.79-3.42) $\beta: 0.24]$ were relevant factors for improving of BDI-II. Conclusion: Depression is an important patient-reported outcome for $\mathrm{QOL}$ in established RA patients. Improving of physical function with joint surgery in both lower and upper limbs caused improving of depression status. Rheumatologists should take the joint surgery into consideration as effective intervention for treatment of established RA patients with treatment.

Acknowledgments: This study was funded by a grant from the Ministry of Health, Labour and Walfare (h2424YN002-00) to Naoki Ishiguro. 